\title{
Cognitive Apprenticeship Learning in Paediatric Clinical Settings
}

\author{
Karen Markussen Linnet*,1, Lise Bols Andersen ${ }^{2}$ and Thomas Balslev ${ }^{2,3}$ \\ ${ }^{I}$ Department of Paediatrics, Aarhus University Hospital, Denmark \\ ${ }^{2}$ Department of Paediatrics, Viborg Regional Hospital, Denmark \\ ${ }^{3}$ MEDU, Centre of Postgraduate Medical Education, Aarhus University, Denmark
}

\begin{abstract}
Objectives: Cognitive apprenticeship learning focuses on improving understanding and clinical diagnostic reasoning among learners. The aim of this study was to describe the feasibility of cognitive apprenticeship encounters in clinical paediatric settings in terms of time consumption; and to describe the encounters in terms of learner and teacher behavior.

Methods: This study was based on data from 485 self-reports filled in by participating learners during a 3-month quality improvement project conducted at three Danish paediatric departments. Teacher and learner cognitive apprenticeship skills training took place at repeated workshops. A total of 59 different learners participated, 4 were medical students, 49 were residents, and 6 were specialists in pediatrics. A total of 75 different teachers participated.

Results: Apprenticeship encounters between teachers and learners lasted median 9 (range 2-120) minutes. In $47 \%$ of the encounters, the teacher and learner examined the child together. In $91 \%$ of the encounters, the learner reported that his or her knowledge was challenged and in $92 \%$ of the encounters, the learners and the teachers verbalized their clinical diagnostic reasoning processes. Educational strategies to reach learning objectives were reported in $77 \%$.

Conclusions: Cognitive apprenticeship learning was a feasible approach to teaching and learning in paediatric departments. Median 9 (range 2-120) minutes were used for the encounters. Almost all learners reported being challenged during the encounter. Almost half of the encounters included a joint teacher and learner examination of a patient.
\end{abstract}

Keywords: Apprenticeship, educational strategies, paediatrics.

\section{BACKGROUND}

Learning often occurs through collaboration with other team members [1-3]. An example is when medical students and residents work together with experienced staff physicians in a clinical setting. Interaction with more experienced clinicians is important for learners to understand the background for clinical activities [4]. Research now provides knowledge about activities that may promote constructive learning in the workplace: opportunities to elaborate and make thinking visible, i.e. externalize and concretize one's own clinical diagnostic reasoning processes $[5,6]$.

One way to promote clinical diagnostic reasoning is to practice cognitive apprenticeship training where residents articulate their thoughts and compare own knowledge and skills with those of an expert $[7,8]$. Among known strategies in cognitive apprenticeship learning are going to the bedside, examination room, outpatient clinic or using the medical record asking for and modeling summary statements [7,8].

Cognitive apprenticeship differs from traditional apprenticeship by extending generalized knowledge to be used in different settings, whereas traditional apprenticeship emphasizes teaching skills in the specific context of their use $[7,8]$. The updated concept of apprenticeship "cognitive appren-

*Address correspondence to this author at the Department of Paediatrics, Aarhus University Hospital, Skejby, Denmark; Tel: 0045-27126687; Fax: 0045-89496023; E-mails: kmlinnet@ki.au.dk, karelinn@rm.dk ticeship" emphasizes, that the focus is on cognitive skills and processes, rather than physical ones $[7,8]$.

There are six teaching models associated with cognitive apprenticeship [7,8]. The first three teaching models are modeling, coaching and scaffolding [7,8]. However, these models are also the core principles in traditional apprenticeship. The teacher is a model, the teacher observes and facilitates the learners' task and the teacher provides support to help the learner perform a task. The next two methods are articulation and reflection $[7,8]$. The teacher encourages the learners to verbalize their knowledge and thinking, and teacher and learner compare their performance with each other. These two models help the learner to focus observations and problem solving strategies. The final method is exploration, which encourages the learner to solve their problems by themselves, i.e. self-directed learning $[7,8]$.

Apprenticeship training based on authentic cases is often hampered by patients' decreased length of stay in hospital, reduced hours or heavy service demands [2]. Information about time required for authentic cognitive apprenticeship situations in clinical practice is sparse. Other aspects of apprenticeship training such as learning outcome and learner and teacher behaviour have rarely been measured in authentic clinical teaching environments [7]. The results of a study by Stalmeijer et al., suggest that cognitive apprenticeship is a useful model for teaching and learning for medical students in clerkships. The results suggest that teacher's lack of time and formal training were the main barriers to cognitive ap- 
prenticeship learning [9]. Likewise, time limitations to bedside teaching in paediatrics have been identified by others [10].

Thus, this study investigated the time consumption of cognitive apprenticeship learning encounters. Moreover, this study documented the frequency of joint examination of a patient; frequency of learner's perception of having their knowledge challenged during the encounter and frequency of verbalization of the clinical reasoning process.

\section{MATERIALS AND METHODOLOGY}

\section{Study Setting}

This prevalence study was based on data from a 3-month quality improvement project designed to support cognitive apprenticeship teaching and learning in clinical paediatric settings. The quality improvement project included an introductory workshop in each of three Danish paediatric departments at Aarhus University Hospital, Skejby, Viborg Regional Hospital and Herning Regional Hospital. In each workshop, 20-35 medical students, residents and faculty participated. By use of illustrative examples, the methods of cognitive apprenticeship: modeling, coaching, scaffolding, articulation, reflection and exploration were briefly introduced by the workshop facilitator (TB) [7,8]. Subsequently the methods were practiced in small groups comprising one or two learners and a senior physician simulating cognitive apprenticeship teaching and learning during analysis of two to three authentic patient video cases each lasting 30-60 seconds [6]. After small-group discussion of each patient video case, each participant volunteered for the whole group the methods as they had been applied; and the workshop facilitator aided a discussion of the advantages and disadvantages of the different methods.

To maximize transfer of cognitive apprentice methods to clinical practice each workshop was concluded by participants identifying optional situations in their department suitable for cognitive apprenticeship encounters. In this way the methods of cognitive apprenticeship teaching methods and their relevance were explicit and brought into the open for teachers as well as learners. After the project period, concluding workshops with debriefing and additional simulated apprenticeship training took place at each department. Methods of cognitive apprenticeship were practiced once more. The duration of workshops was 1.5-2 hours.

\section{Target Population}

All specialists, residents and medical students in clerkship rotations (4 weeks) were invited to participate.

\section{Data Collection}

Immediately after each encounter, learners filled in a 10 item self-report card concerning the encounter and the cognitive processes (Table 1). The learners reported the time spent during the encounter, whether verbalization of clinical reasoning by teacher and learner occurred, whether joint examination of the patient occurred, and whether they felt their knowledge had been challenged. The learner also reported the topic of the encounter, learning outcomes and their plans to learn more. Informed consent was obtained from the study participants at the time they filled in the self-report cart.

\section{ANALYSIS}

Data from all self-report cards from the project was transcribed into and analyzed using Excel. Measures of the time spent during the encounter were missing in 13 self-report cards. The median time spent on apprenticeship training was therefore calculated from results from 472 (97\%) self-report cards. The response rate and positive answers for the remaining questions from the self report cards were calculated and reported in percentages (Table 1), These results are based on the total study group $(\mathrm{n}=485)$.

\section{RESULTS}

A total of 485 self-report cards were completed. A total of 59 different learners participated, 4 were medical students, 49 were residents, and 6 were specialists in paediatrics. A total of 75 different teachers participated.

The median time spent on apprenticeship training was 9 minutes (range: $2-120$ minutes); $(n=472 ; 97 \%)$. In 92\% ( $=$ 485 ) of the encounters the learners and the teachers verbalized their clinical diagnostic reasoning processes. In $47 \%$ of the encounters the learner and teacher examined the child together. In $91 \%$ of the encounters, the learners reported that their knowledge had been challenged.

Table 2 shows examples of the topics of the encounters and the associated clinical reasoning processes. In $77 \%$ of the encounters the learners reported specific learning objectives to be pursued, in textbooks or in clinical guidelines $(40 \%)$, by internet-search $(8 \%)$, by training in the daily clinical practice $(23 \%)$, or by patient follow-up $(16 \%)$. When outcome measures were calculated for each department separately, the results were similar.

\section{DISCUSSION}

In the majority of the encounters, bilateral articulation of clinical diagnostic reasoning occurred. It is important to note that this very desirable outcome [3] occurred in median 9 minutes. In almost half of the encounters, a patient was examined jointly by teacher and learner, illustrating the high authenticity of cognitive apprenticeship encounters. Furthermore, most of the learners reported plans to explore more, i.e. self-directed learning [8]. This means that learning may continue following the encounter [8]. To the authors' knowledge, this is the first report of time expenditure of cognitive apprenticeship encounters from a clinical setting.

The major purpose of this quality improvement project was to support apprenticeship learning in clinical paediatric practice. Using the self-reported cards, we were able to empirically test which specific strategies were used by the learner and teacher, respectively and to describe aspects of professional performance during cognitive apprenticeship encounters $[2,11]$. Almost all participants verbalized their clinical reasoning processes and almost all learners felt that they had been challenged. This suggests that the encounters were indeed cognitive apprenticeship encounters. The documented frequency of the encounters suggests that cognitive apprenticeship encounters can be accomplished, and are feasible for teaching and learning in clinical settings. The authenticity is further underlined by almost half of the situations involving mutual examination of a patient. 
Table 1. Self-Report Card

Response rate for each item are given in italics. Illustrative sample responses by one resident are given.

This card was filled in by the apprentice who had a dialogue with a more experienced colleague and reflected on his or her knowledge and skills.

\begin{tabular}{|c|l|l|l|}
\hline $\begin{array}{c}\text { Hospital, department } \\
\text { Viborg Regional Hospital }\end{array}$ & Date & $\begin{array}{l}\text { Time used } \\
10 \text { minutes }\end{array}$ & $\begin{array}{l}\text { Response rate } \\
97 \%\end{array}$ \\
\hline
\end{tabular}

\begin{tabular}{|c|c|c|c|}
\hline Please answer yes or no & Yes & No & Response rate \\
\hline I explained my findings or thoughts & $\mathrm{x}$ & & $100 \%$ \\
\hline We examined a patient together & $\mathrm{x}$ & & $100 \%$ \\
\hline I felt my knowledge and skills were challenged & $\mathrm{x}$ & & $100 \%$ \\
\hline
\end{tabular}

\section{Please describe the focus of your dialogue}

A small child was admitted with fever. The child was evaluated for a urinary tract infection. A bladder puncture was performed, $100 \%$ to test for infection.

\section{Please describe your clinical reasoning}

My first bladder puncture.

\section{Did you learn during the dialogue?}

Yes, - the technique for bladder ultrasound scan evaluation, bladder puncture, and the indications for the procedures.

\section{What do you plan to do to learn more?}

Present the case to my colleagues at the morning conference.

Name and signature of apprentice

Table 2. Examples of the Learner's Reported Clinical Diagnostic Reasoning Processes

\begin{tabular}{|l|l|l|}
\hline Topics of encounter & What I thought & What I learned \\
\hline \hline $\begin{array}{l}\text { A child with fever and cerebral } \\
\text { irritability. }\end{array}$ & Meningitis? & $\begin{array}{l}\text { Lumbar puncture has to be performed. Assessment of cerebral } \\
\text { status in children. }\end{array}$ \\
\hline Asthma in a four-year-old. & How to decide to treat or not? & $\begin{array}{l}\text { Planning of home measurement of asthma symptoms and peak } \\
\text { flow. }\end{array}$ \\
\hline $\begin{array}{l}\text { Management of a dehydrated } \\
\text { child. }\end{array}$ & Type of dehydration? & I learned about different kinds of intravenous liquid therapy. \\
\hline $\begin{array}{l}\text { A four-week-old child with } \\
\text { jaundice. }\end{array}$ & Causes of jaundice? & Management of neonatal jaundice. \\
\hline
\end{tabular}

It is a strength of this study that experiences from several departments are reported. The results suggest that cognitive apprenticeship teaching and learning is feasible in a variety of clinical settings. Shortcomings of this study are the reliance on a self-report measure, and the extra attention that accompanied the quality improvement project. Both may have inflated the results. On the other hand, it is our clear impression that several encounters with cognitive apprenticeship occurred during the quality improvement project period without filling in of a self-report card. This means that the frequency of encounters is probably underestimated.
It is worth noting, that we have no measures of the prevalence of apprenticeship encounters prior to or after the study period. Likewise, in this study we did not attempt to assess learning outcomes or changes to practice following cognitive apprenticeship encounters. Thus, it cannot be concluded whether the quality improvement project or this study resulted in improved cognitive apprenticeship learning, let alone changes to practice.

\section{CONCLUSION}

This study suggests that cognitive apprenticeship learning in clinical practice is feasible with a median time expen- 
diture of 9 minutes (range 2-120). The quality of the encounters is reflected by almost all learners reported being challenged during the encounter, and the authenticity is shown by almost half of the encounters including a joint examination of a patient.

\section{CONFLICT OF INTERESTS}

None declared.

\section{ACKNOWLEDGEMENTS}

The authors wish to acknowledge the contribution of staff and students at the paediatric departments at Aarhus University Hospital, Skejby, Viborg Regional Hospital and Herning Regional Hospital, without whose co-operation this study would not have been possible. This work was partly funded by The Quality Development Foundation for Education of Residents, Aarhus Denmark.

\section{REFERENCES}

[1] Tynjälä P, Välimaa J, Sarja A. Pedagogical perspectives on the relationships between higher education and working life. Higher Educ 2003; 46: 147-66.
[2] Morris C, BlaneyD. Work-based learning. In: Swanwick T, Ed. Understanding Medical Education. Oxford: Wiley-Blackwell 2010; pp. 69-82.

[3] Teunissen PW, Scheele F, Scherpbier AJ, et al. How residents learn: qualitative evidence for the pivotal role of clinical activities. Med Educ 2007; 41: 763-70.

[4] Teunissen PW, Boor K, Scherpbier AJ, et al. Attending doctors' perspectives on how residents learn. Med Educ 2007; 41: 1050-8.

[5] Dolmans DH, Wolfhagen IH, van der Vleuten CP. Motivational and cognitive processes influencing tutorial groups. Acad Med 1998; 73: S22-4.

[6] Balslev T, de Grave WS, Muijtjens AM, Scherpbier AJ. Enhancing diagnostic accuracy among nonexperts through use of video cases. Pediatrics 2010; 125: e570-6.

[7] Bowen JL. Educational strategies to promote clinical diagnostic reasoning. N Engl J Med 2006; 355: 2217-25.

[8] Collins A. Cognitive Apprenticeship. In: Sawyers RK, Ed. The Cambridge Handbook of the Learning Sciences. USA: Cambridge University Press 2006; pp. 47-59.

[9] Stalmeijer RE, Dolmans DH, Wolfhagen IH, Scherpbier AJ. Cognitive apprenticeship in clinical practice: can it stimulate learning in the opinion of students? Adv Health Sci Educ Theory Pract 2009; 14: 535-6.

[10] Balmer DF, Master CL, Richards BF, Serwint JR, Giardino AP. An ethnographic study of attending rounds in general paediatrics: understanding the ritual. Med Educ 2010; 44: 1105-16.

[11] Miller GF. The Assessment of Clinical Skills/Competance/ Performance. Acad Med 1990; 65: s63-7.

(C) Linnet et al.; Licensee Bentham Open

This is an open access article licensed under the terms of the Creative Commons Attribution Non-Commercial License (http://creativecommons.org/licenses/by-nc/3.0/) which permits unrestricted, non-commercial use, distribution and reproduction in any medium, provided the work is properly cited. 